\title{
Reparo inicial de defeito ósseo crítico na calvária de rato após aplicação de ondas vibratórias
}

\author{
Initial repair of critical bone defect in rat calvary after the application of vibratory \\ waves
}

\author{
Pedro Henrique Andrade Araújo Salvatore Barletta ${ }^{1}$, Isabela Cerqueira Barreto ${ }^{2 *}$, Laise Monteiro Campos \\ Moraes $^{3}$, Eliana dos Santos Câmara Pereira ${ }^{4}$
}

\begin{abstract}
${ }^{1}$ Graduando em Medicina da Faculdade de Medicina da Bahia da Universidade Federal da Bahia; ${ }^{2}$ Graduação em Odontologia. Doutorado em Processos Interativos dos Órgãos e Sistemas (UFBA). É professora de Bioquímica e Biofísica do Instituto de Ciências da Saúde da UFBA; ${ }^{3}$ Graduação em Fisioterapia. Professora Adjunto de Anatomia Humana na Universidade Federal da Bahia. Doutorado em Ciências Morfológicas; ${ }^{4}$ Graduada em Fisioterapia Doutora em Processos Interativos de Órgãos e Sistemas - UFBA
\end{abstract}

\begin{abstract}
Resumo
Introdução: fraturas ósseas extensas representam grande causa de morbidade e geram custos para o serviço de saúde. A vibração de baixa magnitude e alta frequência foi proposta como um tratamento alternativo para aumentar a massa óssea. Objetivo: Avaliar histomorfologicamente o reparo inicial de defeitos ósseos críticos após aplicação de ondas mecânicas vibratórias Metodologia: foram utilizados 10 Rattus norvegicus. Confeccionou-se defeitos críticos de $8,5 \mathrm{~mm}$ de diâmetro na calvária dos ratos. Os animais foram distribuídos em dois grupos: Grupo Controle de Defeito Ósseo (GCDO) e Grupo Experimental de Vibração Imediata (GEVI). Animais do GEVI foram submetidos a ondas vibratórias de $60 \mathrm{~Hz}$ e aceleração vertical de $0,3 \mathrm{~g}$; elas foram aplicadas três vezes/ semana, durante vinte minutos. Após quinze dias do ato operatório, os animais foram eutanasiados para a mensuração da extensão do defeito. Considerando que estes defeitos tinham o mesmo diâmetro inicial, admitiu-se como indicador indireto de deposição osteóide, a redução da extensão linear final dos mesmos. Resultados: observou-se neoformação de matriz osteoide, restrita às bordas ósseas, em ambos os grupos. A média de extensão linear, em milímetros, do defeito ósseo do GEVI foi de $5,83(\mathrm{DP}=0,79)$ e no $G C D O$, foi de 6,62 (DP= 0,63). Não houve diferença estatisticamente significante entre as médias $(U=8,00, z=-1,604, p=0,132)$. Conclusão: evidenciou-se resposta osteogênica a partir da utilização da terapêutica vibratória, contudo de forma estatisticamente não-significante. Deste modo, o presente estudo demonstrou que a utilização das ondas vibratórias não favoreceu um reparo ósseo estatisticamente significante, no período e regime vibratório estudados.
\end{abstract}

Palavras-chaves: Defeito ósseo. Osteogênese. Regeneração óssea. Fratura. Vibração.

\begin{abstract}
Introduction: extensive bone fractures represent a major cause of morbidity and generate costs for the health service. Vibration of low magnitude and high frequency has been proposed as an alternative treatment to increase bone mass. Objective: to evaluate histomorphologically the initial repair of critical bone defects after application of vibrating mechanical waves. Methodology: 10 Rattus norvegicus were used. Critical defects of $8.5 \mathrm{~mm}$ in diameter were made in the calvaria of the rats. The animals were divided into two groups: Bone Defect Control Group (GCDO) and Experimental Immediate Vibration Group (GEVI). GEVI animals were submitted to $60 \mathrm{~Hz}$ vibrating waves and $0.3 \mathrm{~g}$ vertical acceleration; they were applied three times/week, for twenty minutes. Fifteen days after the surgery, the animals were euthanized to measure the extent of the defect. Considering that these defects had the same initial diameter, a reduction in their final linear extension was admitted as an indirect indicator of osteoid deposition. Results: neoformation of an osteoid matrix, restricted to bone borders, was observed in both groups. The mean linear extension, in millimeters, of the GEVI bone defect was $5.83(S D=0.79)$ and in the $G C D O$, it was $6.62(S D=0.63)$. There was no statistically significant difference between the means $(U=8.00, z=-1.604, p=0.132)$. Conclusion: an osteogenic response was evidenced from the use of vibratory therapy, however in a statistically non-significant way. Thus, the present study demonstrated that the use of vibrating waves did not favor a statistically significant bone repair, during the studied period and vibration regime.
\end{abstract}

Keywords: Bone defect. Osteogenesis. Bone Regeneration. Bone Fracture. Vibration.

\section{INTRODUÇÃO}

Correspondente/Corresponding: *Isabela Cerqueira Barreto-Instituto de Ciências da Saúde - Laboratório de Bioengenharia Tecidual e Biomateriais - End: Av. Reitor Miguel Calmon s/n, sala 114 - Vale do Canela CEP: 40.110-100 Salvador, Ba - Tel.: (71) 3283-8943 - E-mail: isabelacbarreto@hotmail.com

Rev. Ciênc. Méd. Biol., Salvador, v. 19, n. 2, p. 311-317, mai./ago. 2020
As fraturas ósseas extensas representam grande causa de morbidade e geram custos para o serviço de saúde. Segundo dados do Sistema de Informações Hospitalares do Sistema Único de Saúde (SIH/SUS), o valor total gasto com fraturas de ossos de membros no Brasil foi de, aproximadamente, 577 milhões de reais no ano de 2018 .

O processo de cura de uma fratura é composto por três fases que se sobrepõem: (1) inflamatória; (2) 
reparativa; e (3) remodelagem ${ }^{1}$. Na fase inflamatória, os macrófagos são inicialmente recrutados para remover o tecido necrótico, patógenos, detritos e, também secretam moléculas, as quais ajudam a promover a angiogênese no local de fratura ${ }^{1}$. Na fase reparativa, a via de sinalização Wnt/ $\beta$-catenina desempenha importante função, sendo a via dominante na regulação da diferenciação osteoblástica ${ }^{2}$. As atividades da vida diária geram estímulos mecânicos sobre o esqueleto humano, contribuintes para remodelagem óssea e consolidação da área fraturada na terceira fase do processo de cura ${ }^{3,4}$.

O termo "defeito ósseo crítico" foi originalmente conceituado por Schmitz e Hollinger ${ }^{21}$ apud, Vargel ${ }^{5}$ como sendo o defeito ósseo de menor tamanho em um osso específico de determinada espécie que não irá se curar espontaneamente durante a vida do animal ${ }^{5}$. Para a avaliação do exato potencial osteogênico de intervenções que visam melhorar o reparo ósseo, a confecção de defeito ósseo crítico em modelos animais é essencial, uma vez que a propriedade regenerativa nesta condição não é capaz de regenerar o tecido ósseo isoladamente, deste modo, sendo possível observar a real contribuição das terapêuticas aplicadas ${ }^{6}$.

A vibração de corpo inteiro (whole body vibration, WBV) é definida como ondas vibratórias mecânicas transmitidas ao corpo ${ }^{4}$. Estudos demonstram efeito das vibrações diretamente sobre as células que compõem o tecido ósseo, sendo a via de sinalização $\mathrm{Wnt} / \beta$-catenina a chave para o efeito anabólico observado ${ }^{7,8}$.

Desta forma, decidiu-se investigar, por meio de análise histomorfométrica, os resultados observados no emprego da terapêutica com WBV no pós-operatório imediato, para aceleração do reparo de defeito ósseo crítico em calvária de rato. Assim, justifica-se este estudo, em virtude da importância de se buscar alternativas para o tratamento das fraturas ósseas, diante dos impactos socioeconômicos que elas proporcionam.

\section{METODOLOGIA}

\section{Considerações éticas, bioéticas e deontológicas}

O estudo realizado trata-se de um estudo de intervenção, de experimentação animal. O projeto desta pesquisa foi submetido e aprovado pela Comissão de Ética no Uso de Animais do Instituto de Ciências da Saúde da Universidade Federal da Bahia (CEUA ICS-UFBA), sendo registrado com o $\mathrm{n}$ - 108/2016. Todos os procedimentos estiveram de acordo com os preceitos da Lei no 11.794 , de 8 de outubro de 2008, do Decreto no 6899, de 15 de julho de 2009, e com as normas editadas pelo Conselho Nacional de Controle de Experimentação Animal (CONCEA).

\section{Animais}

Foram utilizados 10 Rattus norvegicus, da linhagem Wistar albinus, machos, com massa corporal entre 350 e $450 \mathrm{~g}$. Os animais foram mantidos durante todo período experimental em caixas plásticas identificadas, forradas com maravalha de pinus autoclavada e trocada diariamente. Foram alimentados com ração sólida da Nuvital ${ }^{\circ}$ (Paraná, Brasil) e água ad libitum.

\section{Composição dos grupos e número amostral}

Os animais foram distribuídos de forma aleatória para a composição de dois grupos, com 5 animais em cada:

- Grupo Controle de Defeito Ósseo (defeito ósseo sem aplicação de ondas vibratórias) - GCDO: A calvária foi submetida à criação do defeito ósseo crítico e não houve intervenção alguma. As lâminas histológicas e a análise qualitativa apresentadas, referentes a este grupo, foram obtidas por Carvalho et al. ${ }^{9}$. A análise histomorfométrica das mesmas foi realizada no presente estudo.

- Grupo Experimental de Vibração Imediata GEVI: A calvária de cada animal foi submetida à criação do defeito ósseo crítico e os animais foram submetidos às ondas vibratórias no pós-operatório imediato (POI).

Foram avaliados após um período de quinze dias de pós-operatório.

\section{Procedimentos cirúrgicos}

Os procedimentos cirúrgicos foram realizados de acordo com o protocolo descrito por Miguel et al. e por Câmara-Pereira ${ }^{10,11}$ (FIGURA 1). Os animais foram submetidos a anestesia, com injeção intramuscular de cloridrato de quetamina, na proporção de $0,8 \mathrm{~mL} / 100 \mathrm{~g}$ de massa corpórea, e a analgesia e sedação com injeção intramuscular de cloridrato de xilazina, na proporção de $0,04 \mathrm{~mL} / 100 \mathrm{~g}$ de massa corpórea.

Os animais foram posicionados em decúbito ventral, para acesso à calvária. Em seguida, a incisão cutânea bicoronal, semilunar, foi realizada, com aproximadamente 3,0 cm de extensão; foi prosseguida por divulsão e elevação do retalho para acesso à calvária.

Para confecção do defeito ósseo de $8,5 \mathrm{~mm}$ de diâmetro, foi utilizada uma fresa trefina de $8 \mathrm{~mm}$, montada em contra-ângulo com redução de 1:16, acoplada em motor cirúrgico com $1500 \mathrm{rpm}$. Para finalizar, foi realizada a sutura da incisão cirúrgica com fio de seda 4.0. 
Figura 1 - Procedimento cirúrgico para elaboração do defeito ósseo crítico na calvária dos ratos. A) Diérese B) Exposição do tecido ósseo C) Confecção do defeito ósseo com fresa trefina D) Marcação do defeito ósseo E) Remoção do fragmento ósseo F) Reposicionamento do retalho tecidual e sutura.
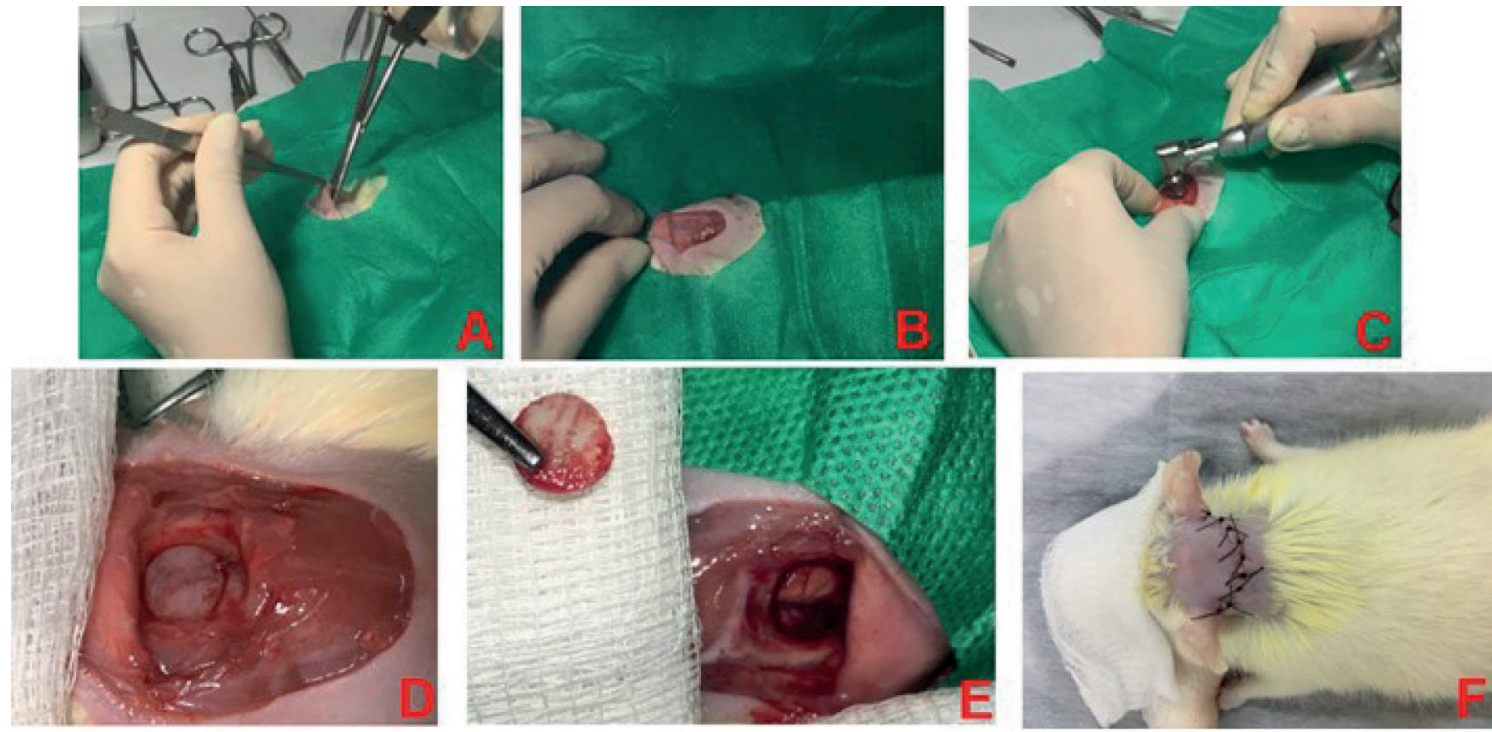

Fonte: Elaborada pelo autor

\section{Placa vibratória}

Os animais do GEVI foram submetidos a ondas vibratórias de $60 \mathrm{~Hz}$ de frequência e aceleração vertical de $0,3 \mathrm{~g}$, as quais foram aplicadas sistemicamente nos ratos, três vezes por semana, durante 20 minutos, por quinze dias. Este protocolo foi estabelecido após a realização de experimentos-piloto prévios.

O equipamento Juvent $1000^{\circ}$ (Tennessee, Estados Unidos) foi utilizado para gerar as ondas vibratórias na terapêutica sistêmica dos animais. Depois da etapa cirúrgica, após a recuperação da narcose anestésica, no primeiro dia do pós-operatório, os ratos do GEVI receberam as ondas mecânicas vibratórias.

Apenas os ratos deste grupo foram mantidos cada um sobre a plataforma vibratória, cuja periferia foi protegida por uma caixa acrílica, a fim de assegurar a administração da terapêutica proposta (FIGURA 2).

Figura 2 - Aplicação da terapêutica vibratória.

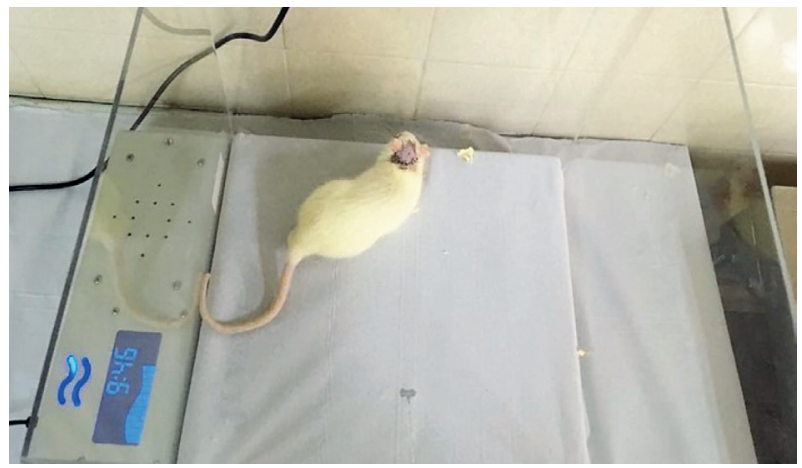

\section{Obtenção das amostras de calvárias e processamento histológico}

Após os quinze dias contabilizados a partir do ato operatório, os animais foram eutanasiados com doses letais de cloridrato de quetamina intramuscular. Após a morte, os ratos foram dissecados para a remoção de toda a porção superior da calvária. Os espécimes foram divididos em duas partes, em uma proporção de dois terços anteriores e um terço posterior das calvárias de todos os ratos.

Após fixação em formol tamponado a $4 \%$ durante quatro dias, os fragmentos que incluíam o segmento anterior da calvária, estendendo-se $2 \mathrm{~mm}$ além do defeito, foram descalcificados com EDTA a 7\% por sete dias.

Os espécimes descalcificados foram preparados por um processador automático de tecido (LEICA ${ }^{*}$ - Nussloch, Alemanha). As amostras teciduais emblocadas em parafina foram cortadas em micrótomo. Os cortes seriados, de $5 \mu \mathrm{m}$ de espessura, foram alocados sobre lâminas previamente tratadas com silano. Os cortes histológicos foram corados com hematoxilina e eosina (HE).

\section{Cegamento da análise dos resultados}

Posteriormente à confecção das 10 lâminas referentes aos espécimes coletados, um sorteio simples foi realizado, atribuindo, deste modo, um número (de 1 até 10) aleatoriamente para cada lâmina. Após esta numeração, uma tabela foi elaborada com as devidas correspondências entre as lâminas e os grupos de estudo. $O$ indivíduo que analisou histomorfometricamente as lâminas o fez sem ter acesso à tabela.

Fonte: Elaborada pelo autor 


\section{Análise histomorfométrica e estatística}

Foi realizada a avaliação histomorfométrica, a partir das imagens obtidas através de microscopia de luz comum, para mensuração da extensão linear do defeito ósseo em milímetros (FIGURA 3). As medidas foram realizadas, adotando como pontos de referência para a mensuração o limite da deposição da matriz osteoide neoformada nas periferias do defeito ósseo, de borda a borda. Considerando que estes defeitos confeccionados nas calvárias tinham o mesmo diâmetro inicial $(8,5 \mathrm{~mm})$, admitiu-se como indicador indireto de deposição osteoide e, consequente progressão para o reparo ósseo, a redução da extensão linear final dos mesmos.

Os dados obtidos foram analisados no Statistical $\mathrm{Pa}$ ckage for the Social Sciences 23 (IBM SPSS Statistics 23, Software, Inc). Os dados quantitativos foram expressos como média e desvio padrão (DP). Para realização da análise estatística, foi aplicado o teste não paramétrico Exato de Mann-Whitney. Os valores de $\mathrm{p}<0,05$ foram considerados significativos. Os resultados obtidos foram apresentados de forma descritiva e através de gráfico.

Figura 3 - Desenho esquemático do defeito ósseo crítico em calvária de rato A) Vista superior; B) Corte coronal da extensão linear da área seccional.
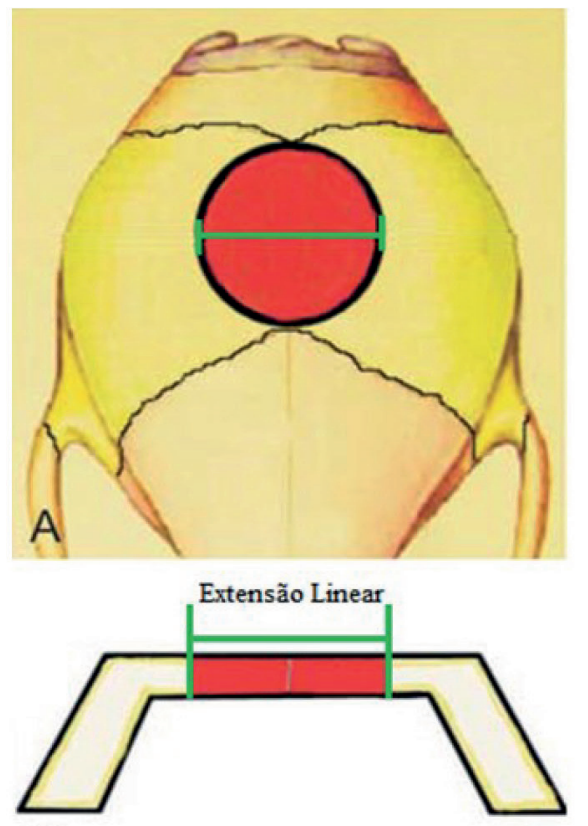

B

Fonte: Adaptada de Rolim ${ }^{12}$

\section{RESULTADOS}

\section{Grupo Controle de Defeito Ósseo - GCDO}

Em estudo prévio e em condições similares às do presente estudo, Carvalho et al. (2010) observaram o padrão de resposta tecidual deste grupo ${ }^{9}$. No ponto biológico de quinze dias, foi observada, de forma incipiente, neoformação óssea que se limitou à borda do defeito ósseo confeccionado, onde se notaram osteoblastos de aspecto ativo (FIGURA 4A). Já na região central do defeito, identificou-se a deposição de tecido conjuntivo frouxo e a neoformação de capilares sanguíneos (FIGURA 4B).

Figura 4 - GCDO - A) Região de borda; B) Região central do defeito ósseo; VS: vasos sanguíneos; OC: osteócitos; MON: matriz osteoide neoformada; TC: tecido conjuntivo; VC: veia central.
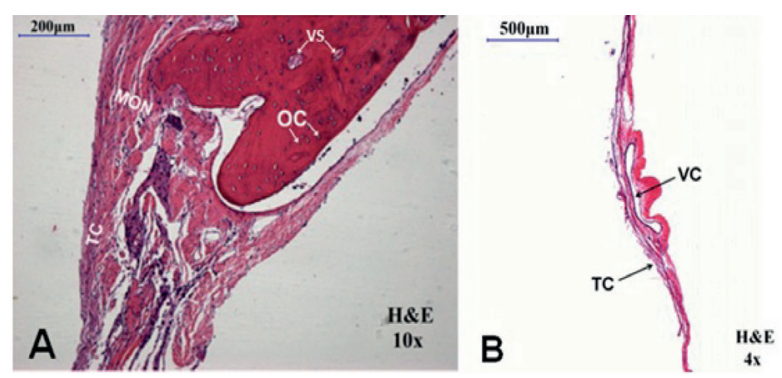

Fonte: Adaptada de Carvalho ${ }^{9}$.

\section{Grupo Experimental de Vibração Imediata - GEVI}

Observou-se a neoformação de matriz osteoide reparativa, restrita às bordas ósseas, que se direcionava ao centro do defeito (FIGURA 5A).

Na região central do defeito ósseo, notou-se tecido conjuntivo frouxo, com áreas hemorrágicas e edemaciadas, fibroblastos ativos, além de infiltrado inflamatório mononuclear, com pequena quantidade de linfócitos (FIGURAS 5B e 5C). As áreas de hemorragia eram antigas e mais pronunciadas na periferia do defeito ósseo.

Identificaram-se áreas focais de matriz osteoide ao longo do defeito, as quais correspondiam à aproximadamente um quinto da extensão do mesmo. Nestas áreas de neoformação osteoide, a hemorragia era menos evidente nas suas proximidades. Observaram-se osteoblastos alinhados e ativos e osteócitos que se apresentaram com a característica de menor atividade. 
Figura 5 - GEVI - A) Região de borda; B) e C) Região central do defeito ósseo; OC: osteócitos; MON: matriz osteoide neoformada; TC: tecido conjuntivo; VC: veia central.

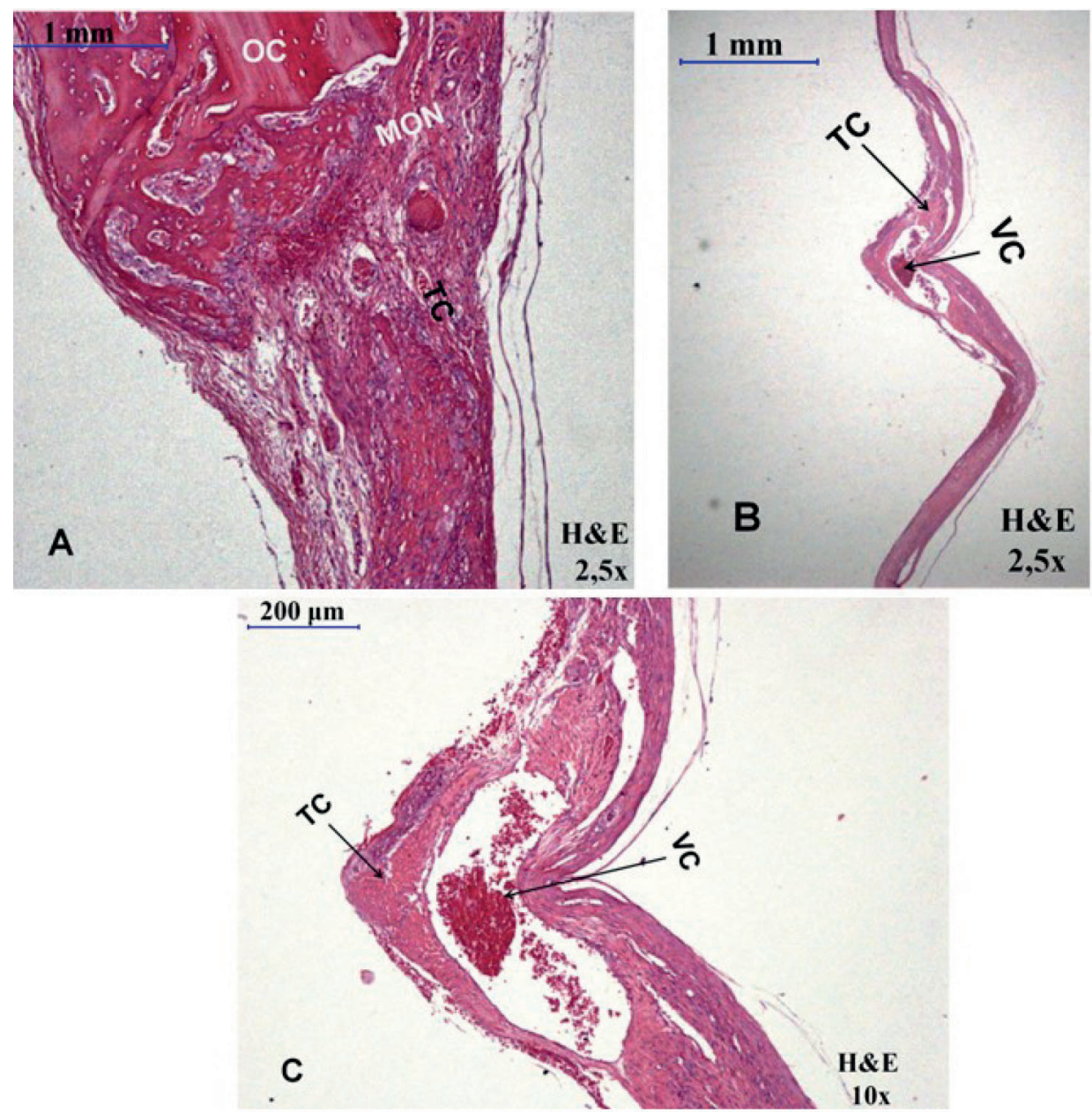

Fonte: Elaborada pelo autor

\section{Análise Morfométrica}

No gráfico 1, observa-se as médias dos valores de extensão linear do defeito ósseo das calvárias dos ratos de cada grupo experimental.

A distribuição das mensurações não foi similar entre os dois grupos, de acordo com a inspeção visual dos histogramas correspondentes. A média de extensão linear, em milímetros, do defeito ósseo do GEVI foi de 5,83 $(D P=0,79) ;$ já a média de extensão linear, em milímetros, do GCDO foi de 6,62 (DP=0,63). Não houve diferença estatisticamente significante entre as médias $(U=8,00$, $z=-1,604, p=0,132)$.
Gráfico 1 - Média dos valores de extensão linear do defeito ósseo em milímetros

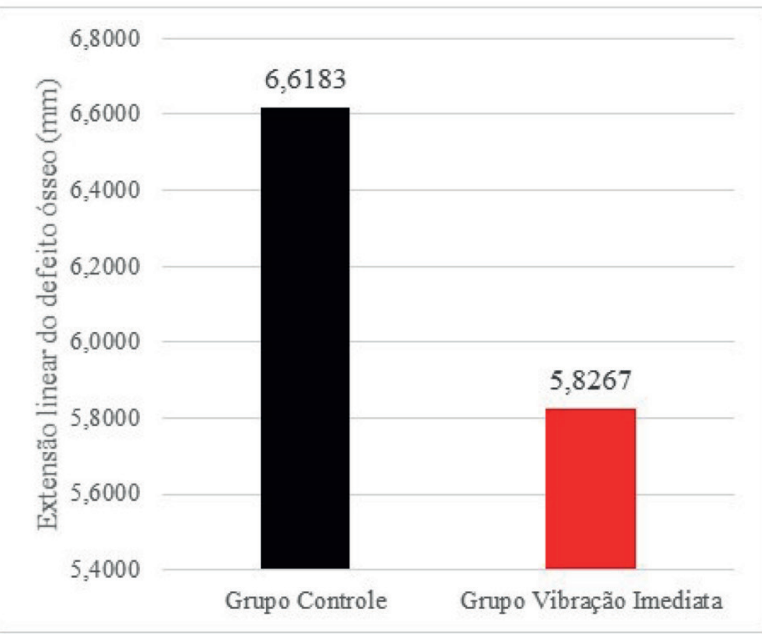

Fonte: Elaborada pelo autor 


\section{DISCUSSÃO}

Os parâmetros mais comumente utilizados para caracterizar as vibrações na terapêutica com a WBV são a frequência da vibração (em Hertz; $1 \mathrm{~Hz}=1$ oscilação/s), amplitude (altura da onda em milímetros) e/ou a magnitude do pico, que é expressa como a aceleração vertical da onda (em $\mathrm{m} / \mathrm{s}^{2}$, muitas vezes apresentada como múltiplos da aceleração gravitacional da Terra ao nível do mar - g; $\left.1 \mathrm{~g}=9,81 \mathrm{~m} / \mathrm{s}^{2}\right)^{3,13}$.

Em particular, a vibração de baixa magnitude e alta frequência (Low Magnitude and High Frequency Vibration, LMHFV: $\leq 1,0 \mathrm{~g}$ de aceleração de pico e frequência na faixa de $30 \mathrm{a} 90 \mathrm{~Hz}$ ) foi proposta como um tratamento alternativo e seguro para aumentar a massa óssea ${ }^{14}$, enquanto que a de alta magnitude $(>1,0 \mathrm{~g})$ não apresenta resultados positivos ${ }^{13}$. Deste modo, optou-se neste estudo pelas vibrações de $60 \mathrm{~Hz}$ e aceleração vertical de 0,3 g, enquadradas nos parâmetros da LMHFV.

Em estudos experimentais com animais, foi demonstrado que a WBV de baixa magnitude aplicada em ratos e camundongos mostrou efeitos anabolizantes no osso com taxas aumentadas de formação óssea e aumento do volume ósseo trabecular ${ }^{15,16}$. Wang et al. ${ }^{16}$ através de revisão sistemática, que teve como objetivo investigar a ação da WBV no reparo de defeitos ósseos em modelos animais, revelaram que 15 dos 19 estudos incluídos demonstraram que a vibração teve um efeito positivo, sendo que a maioria dos estudos analisados utilizou a LMHFV ${ }^{16}$.

A via de sinalização de Wnt está envolvida em vários aspectos no crescimento de muitos órgãos e tecidos, tendo atuação importante durante o desenvolvimento embrionário e na manutenção de tecidos autorrenováveis $^{17}$. Esta via pode ser dividida em uma via de sinalização canônica Wnt, que depende da função da $\beta$-catenina (via Wnt/ $\beta$-catenina), e as vias Wnt não canônicas que operam independentemente da $\beta$-catenina ${ }^{17}$.

A via de sinalização $W n t / \beta$-catenina assume papel essencial no reparo de fraturas ósseas ${ }^{2}$. Desde os estágios iniciais do reparo, a $\beta$-catenina atua para que as células mesenquimais pluripotentes se diferenciem em osteoblastos ou condrócitos, necessários para o processo de osteogênese ${ }^{17}$.

Contudo, a via de sinalização canônica Wnt possui efeitos osteogênicos opostos dependendo do estágio de maturação das células-tronco mesenquimais envolvidas. A proteína Wnt3a induz osteogênese quando esta molécula é utilizada para estimular tal via de sinalização em osteoblastos maduros da calvária de camundongos, enquanto ela, ou a $\beta$-catenina ativada constitutivamente, inibem a diferenciação osteogênica de células mesenquimais indiferenciadas ${ }^{18}$. Isto implica que os estimulantes de sinalização de $W n t / \beta$-catenina usados para promover o reparo de fraturas devem ser utilizados somente após as células mesenquimais estarem comprometidas com a linhagem dos osteoblastos, para se atingir melhores resultados.
Considerando que, ao se estimular a via de sinalização canônica Wnt nas células osteoprogenitoras ainda não comprometidas com a linhagem osteoblástica, ao invés de ajudar, há prejuízo da osteogênese ${ }^{18} \mathrm{e}$, diante do fato de que um possível mecanismo pelo qual a WBV obtém suas respostas é justamente a estimulação desta via ${ }^{7}$, o pós-operatório imediato pode não ter sido momento oportuno para o início da intervenção. Embora tenha sido observada a diminuição da extensão linear do defeito ósseo na calvária dos ratos tratados com a WBV em comparação ao grupo controle, a diferença entre as médias das mensurações não foi estatisticamente significante.

Outros estudos, assim como este, não revelaram melhora significativa no reparo de fraturas ósseas em ratos, com o uso da terapêutica vibratória ${ }^{19,20}$. Wehrle et al. ${ }^{19}$ demonstraram que as vibrações de $35 \mathrm{~Hz} / 0,3 \mathrm{~g}$ não contribuíram para o reparo de defeitos ósseos e que as vibrações de $45 \mathrm{~Hz} / 0,3 \mathrm{~g}$ atuaram negativamente, prejudicando a ossificação ${ }^{19}$. Komrakova et al. ${ }^{20}$, por sua vez, concluíram que a vibração $(70 \mathrm{~Hz})$ sozinha não alterava os parâmetros ósseos e que, se associada à um fármaco antiosteoporótico, em situações de fratura, acarretava efeitos negativos no reparo ósseo ${ }^{20}$.

Todavia, é necessário ressaltar a heterogeneidade dos protocolos de terapêutica vibratória encontrados na literatura, bem como os diferentes modelos animais e de defeitos ósseos utilizados, o que dificulta a comparação de resultados. A maioria dos trabalhos correlatos investigaram o reparo de defeitos confeccionados em fêmur ou em tíbia; estes ossos recebem carga mecânica naturalmente, o que pode influenciar os resultados obtidos. Esta variável de confusão é eliminada com o uso de defeitos ósseos produzidos em calvária. A opção por defeito ósseo crítico em calvária de rato, com o diâmetro de $8 \mathrm{~mm}$, é amplamente adotada em estudos que analisam o potencial osteogênico de diferentes intervenções ${ }^{6,11}$.

Como limitações, têm-se o ponto biológico curto de quinze dias, que pode não ter sido suficiente para a demonstração da associação entre a terapêutica vibratória e o reparo ósseo estatisticamente significante. Os animais do grupo controle não foram manipulados e confinados sobre a placa vibratória desligada, para simular o tratamento. Isto pode ter implicado em condições de estresse distintas para os grupos de animais, além do fato dos locais experimentais terem sido diferentes. Neste estudo, utilizou-se como indicador indireto do reparo ósseo a redução da extensão linear do defeito ósseo crítico. Esta metodologia desconsidera a deposição de matriz osteoide ao longo do defeito, de modo que técnicas de demonstração direta de neoformação óssea, como uso de corantes específicos, poderiam ter sido utilizadas. Estas variáveis podem ter influído nos resultados observados.

Algo que poderia ter sido considerado seria a investigação do melhor momento para a intervenção da terapêutica vibratória. Levando-se em conta a necessidade de se esperar certo tempo para a diferenciação osteoblástica das células-tronco mesenquimais para obtenção de me- 
Ihores resultados ${ }^{18}$, um grupo experimental recebendo a WBV após maior intervalo de tempo pós-operatório poderia revelar incrementos maiores na osteogênese.

Novos estudos com pontos biológicos mais longos devem ser realizados para a confirmação da tendência de evolução para o reparo ósseo, induzida pela aplicação de vibrações, mantendo-se a opção por defeitos ósseos críticos. A elucidação do melhor momento no pós-operatório para se realizar a intervenção com ondas vibratórias também deve ser objetivada em futuros trabalhos, sendo tão relevante quanto a definição dos protocolos ideais de regime vibratório. As combinações da vibração com outros tipos de intervenções que visam o favorecimento do reparo ósseo necessitam, da mesma forma, serem avaliadas.

\section{CONCLUSÃO}

$\mathrm{Na}$ análise qualitativa das lâminas, foi observada deposição de matriz osteoide ao longo do defeito ósseo, enquanto que, na análise histomorfométrica, demonstrou-se a redução de sua extensão linear final (indicador indireto da evolução para o reparo do defeito), evidenciando-se, assim, resposta osteogênica a partir da utilização da terapêutica vibratória, contudo de forma estatisticamente não significante. Deste modo, o presente estudo demonstrou que a utilização das ondas vibratórias não favoreceu um reparo ósseo estatisticamente significante, no período e regime vibratório estudados.

\section{REFERÊNCIAS}

1. COTTRELL, J.A. et al. The biology of bone and ligament healing. Foot Ankle Clin, New Jersey, v. 21, p. 739-761, 2016. DOI: 10.1016/j. fcl.2016.07.017

2. JIN, H. et al. Anti- DKK1 antibody promotes bone fracture healing through activation of beta-catenin signaling. Bone, Zhejiang, v. 71, p. 63-75, Fev. 2015. DOI: 10.1016/j.bone.2014.07.039

3. CERCIELLO, S. et al. Clinical applications of vibration therapy in orthopaedic practice. Muscles Ligaments Tendons J., Padova, v. 6, n. 1, p. 147-156, 2016. DOI: 10.11138/mltj/2016.6.1.147

4. SWE, M. et al. Role of the whole body vibration machine in the prevention and management of osteoporosis in old age: a systematic review. Malay. J. Med. Sci., Jalan Green town, v. 23, n. 5, p. 8-16, Out. 2016. DOI: $10.21315 / \mathrm{mjms} 2016.23 .5 .2$

5. VAJGEL, A. et al. A systematic review on the critical size defect model. Clin. Oral Implants. Res., Londres, v. 25, n. 8, p. 879-93, Ago. 2014. DOI: 10.1111/clr.12194

6. CAMPOS, L. S. Estudo do comportamento biológico de biomaterial xenogénico em defeito ósseo crítico. 2012. Dissertação (Mestrado em Ciências Biomédicas e Medicina) - Universidade do Algarve, Faro, Portugal, 2012.

7. JING, D. et al. Effect of low-level mechanical vibration on osteogenesis and osseointegration of porous titanium implants in the repair of long bone defects. Sci. Rep., Xi'an, v. 5, p. 17134, Nov. 2015. DOI: 10.1038/ srep17134

8. JING, D. et al. Low-level mechanical vibration improves bone microstructure, tissue mechanical properties and porous titanium implant osseointegration by promoting anabolic response in type 1 diabetic rabbits. Bone, Xi'an, v. 106, p. 11-21, Out. 2018. DOI: 10.1016/j. bone.2017.10.001.

9. CARVALHO, A.A. Reparo ósseo de defeito crítico em calvária de rato com microesferas de hidroxiapatita e selante de fibrina. 2010. Dissertação (Mestrado em Processos Interativos dos Órgãos e Sistemas) - Universidade Federal da Bahia, Instituto de Ciências da Saúde, Salvador, 2010.

10. MIGUEL, F.B. et al. Morphological assessment of the behavior of three-dimensional anionic collagen matrices in bone regeneration in rats. J. Biomed. Mater. Res., Salvador, v. 78, p. 334-9, Fev. 2006; DOI: 10.1002/jbm.b.30492

11. CÂMARA-PEREIRA, E. Análise tecidual óssea após aplicação de ondas vibratórias e associações. 2013. Tese (Doutorado em Processos Interativos de Órgãos e Sistemas) - Instituto de Ciências da Saúde da Universidade Federal da Bahia, Salvador, 2013.

12. ROLIM, A.E.H. Avaliação de microesferas de hidroxiapatita, dopadas ou não com estrôncio, no reparo de defeito crítico, em calvária de rato. 2010. Dissertação (Mestrado em Odontologia) - Universidade Federal da Bahia, Faculdade de Odontologia, Salvador, 2010.

13. MA, C. et al. Effect of whole-body vibration on reduction of bone loss and fall prevention in postmenopausal women: a meta-analysis and systematic review. J. Orthop. Surg. Res., Hangzhou, v. 11, p. 24, 2016. DOI: 10.1186/s13018-016-0357-2

14. RUBIN, C. et al. Anabolism. Low mechanical signals strengthen long bones. Nature, New York, v. 412, p. 603-4, 2001. DOI: 10.1038/35088122

15. GONG, H. et al. Whole body vibration with rest days could improve bone quality of distal femoral metaphysis by regulating trabecular arrangement. Sci. China Life Sci., Beijing, v. 13, July 2018. DOI: 10.1007/ s11427-017-9253-x

16. WANG, J. et al. The effect of whole body vibration on fracture healing - a systematic review. Eur. Cell Mater, Hong Kong, v. 34, p. 108-127, 2017. DOI: $10.22203 /$ eCM.v034a08

17. DUAN, P.; BONEWALD, L.F. The role of the wnt $/ \beta$-catenin signaling pathway in formation and maintenance of bone and teeth. Int. J. Biochem. Cell Biol., Kansas City, v. 77, p. 23-29, Ago. 2016. DOI: 10.1016/j.biocel.2016.05.015

18. WANG, T.; ZHANG, X.; BIKLE, D.D. Osteogenic differentiation of periosteal cells during fracture healing. J. Cell Physiol., New York v. 232, p. 913-921, May 2017. DOI: 10.1002/jcp.25641

19. WEHRLE, E. et al. Distinct frequency dependent effects of whole-body vibration on non-fractured bone and fracture healing in mice. J. Orthop. Res., Hamburg, v. 32, n. 8, p. 1006-13, Ago. 2014. DOI: 10.1002/jor.22629

20. KOMRAKOVA, M. et al. The Effect of vibration treatments combined with teriparatide or strontium ranelate on bone healing and muscle in ovariectomized rats. Calcif. Tissue Int., Göttingen, v. 99, n. 4, p. 408-22, Oct. 2016. DOI: 10.1007/s00223-016-0156-0

21. SCHMITZ, J. P.; HOLLINGER, J. O. The critical size defect as an experimental model for craniomandibulofacial nonunions. Clin. Orthop. Relat. Res., Philadelphia, n. 205, p. 299-308, 1986.

Submetido em: 22/10/2019

Aceito em: 14/05/2020 